\title{
Research Note \\ The Impact of Sound-Field Systems on Learning and Attention in Elementary School Classrooms
}

\author{
Julie E. Dockrell ${ }^{a}$ and Bridget Shield ${ }^{b}$
}

\begin{abstract}
Purpose: The authors evaluated the installation and use of soundfield systems to investigate the impact of these systems on teaching and learning in elementary school classrooms.

Methods: The evaluation included acoustic surveys of classrooms, questionnaire surveys of students and teachers, and experimental testing of students with and without the use of sound-field systems. In this article, the authors report students' perceptions of classroom environments and objective data evaluating change in performance on cognitive and academic assessments with amplification over a 6-month period.

Results: Teachers were positive about the use of sound-field systems in improving children's listening and attention to verbal instructions. Over time, students in amplified classrooms did not differ from those in nonamplified classrooms in their reports of listening conditions, nor did their performance differ in measures of numeracy, reading, or spelling. Use of sound-field systems in the classrooms resulted in significantly larger gains in performance
\end{abstract}

in the number of correct items on the nonverbal measure of speed of processing and the measure of listening comprehension. Analysis controlling for classroom acoustics indicated that students' listening comprehension scores improved significantly in amplified classrooms with poorer acoustics but not in amplified classrooms with better acoustics.

Conclusions: Both teacher ratings and student performance on standardized tests indicated that sound-field systems improved performance on children's understanding of spoken language. However, academic attainments showed no benefits from the use of sound-field systems. Classroom acoustics were a significant factor influencing the efficacy of sound-field systems; children in classes with poorer acoustics benefited in listening comprehension, whereas there was no additional benefit for children in classrooms with better acoustics.

Key Words: classroom acoustics, sound-field systems, learning
$M$ uch of the teaching and learning in schools is established through talking and listening. Poor listening environments have detrimental effects on students' ability to attend to and process relevant aspects of the acoustical signals in classrooms and compromise learning and achievement (McSporran, 1997; Picard \& Bradley, 2001). There is an increasing awareness of the specific ways in which poor classroom acoustics can impact students' learning and attainment and evidence that particular groups of students are differentially at risk. A wide range of attainments and performance factors have been examined to establish the

\footnotetext{
${ }^{a}$ Institute of Education, London, England

${ }^{\mathrm{b}}$ London South Bank University

Correspondence to Julie Dockrell: j.dockrell@ioe.ac.uk

Editor: Sid Bacon

Associate Editor: Charissa Lansing

Received January 31, 2011

Revision received June 20, 2011

Accepted December 24, 2011

DOI: 10.1044/1092-4388(2011/11-0026)
}

effects of environmental noise, including literacy, attention, mathematics, and memory (Cohen, 1980; Cohen, Evans, Krantz, \& Stokols, 1980; Cohen, Krantz, Evans, Stokols, \& Kelly, 1981; Cohen \& Weinstein, 1981; Shield \& Dockrell, 2008). Tasks that involve language, such as reading and word problems in mathematics, and those that have high cognitive-processing demands involving attention, problem solving, and memory appear to be particularly vulnerable to exposure to noise (Evans \& Lepore, 1993; Shield \& Dockrell, 2008), although such effects are not always evident (Cohen et al., 1980, 1981). A significant factor governing the potential impact of noise is the classroom's internal and external acoustic environment (Shield \& Dockrell, 2004; Stansfeld et al., 2005). A number of attempts have been made to address these negative acoustic factors, including more stringent government standards such as those in the United States and the United Kingdom (American National Standards Institute/Acoustical Society of America [ANSI/ASA], 2010; Department for Education and Skills, 2003). However, regulations are difficult to introduce retrospectively and are not necessarily adhered to. Hence, alternative methods of modifying the acoustic 
environment - for example, installing sound amplification, or sound-field systems - are appealing alternatives. Establishing the efficacy of such modifications for different student groups and different classroom conditions is an essential step in developing evidence-based practice.

\section{Sound-Field Systems}

Sound amplification offers the possibility of immediately minimizing the impact of poor classroom acoustics on students' learning. Sound-field systems work by projecting the teacher's voice so that children are predicted to have a better opportunity to hear clearly the teacher's instructions. These systems do not reduce exposure to external sound sources but importantly, by raising the level of the teacher's voice, they can increase the level of the speech signal relative to levels of external and internal sound sources. Initially, sound-field systems were used to support students with hearing problems; however, the technology is now promoted widely for use in mainstream classrooms. Many claims about the wideranging positive impacts of these systems have been made in the media and in recommendations for practice. For example, McSporran (1997, p. 16) argues that "possibly the most cost-effective, appropriate and acceptable way of maximizing the classroom acoustic environment is through the use of signal-to-noise enhancing technology." By hearing what is being taught, every child benefits and enjoys a higher degree of achievement (Flexer, Biley, Hinckley, Harkema, \& Holcomb, 2002, p. 38). Sound-field systems have the added benefit of reducing the strain on teachers' voices (Jónsdottir, Laukkanen, \& Siikki, 2003). To identify specific effects on learning environments and students' attainments, it is necessary to devise complex studies. Reports of the benefits of sound-field systems need to control for the initial levels of performance of students in the target classrooms and relate changes to those typically experienced by students in matched classrooms who do not have the benefit of these systems. Without comparison groups and baseline measures on target skills, it is not possible to attribute any changes to the system, per se, because teachers and classes that use the system may not be representative, and simply introducing something different to the classroom can produce a novelty effect for students and teachers alike. It is, therefore, also useful to include measures of academic and cognitive performance that are independent of teacher assessment and to carry out studies that examine the effects of sound-field systems at different ages because the younger the child, the greater the detrimental effect of noise and reverberation (Bradley \& Sato, 2008). Robust evaluations should include information about the acoustics of the classrooms to identify specifications for beneficial use of the systems (Rosenberg et al., 1999).

\section{The Evidence Base}

First, we consider studies that evaluate the impact of amplification on teachers' and students' voices; then, we consider teachers' and students' ratings of listening behavior; and, finally, we examine studies that have extended our understanding of the impact of amplification on academic performance.

Amplification of the teacher's (and student's) voice is the main purpose of sound-field systems. As such, sound-field systems should create a more favorable signal-to-noise ratio (SNR) than is generally available in the classroom. Changes in mean speech recognition performance in amplified classrooms have been reported, and these improvements are consistent across different positions in the classroom, maintaining a level that is optimal for speech recognition even in noisy conditions (Larsen \& Blair, 2008). Larsen and Blair (2008) also noted the additional SNR advantage for students when a hand-held microphone was used during class discussions or for oral reading. The extent to which improved SNR provides wider benefits in the classroom has been the focus of a number of research studies. Decreased vocal strain is one of the greatest benefits recorded for sound-field systems by teachers (Rosenberg, et al., 1999). Teachers are at high risk of vocal abuse and voice problems, compared with those in nonteaching professions (Jónsdottir, 2010). The use of sound-field systems has consistently been shown to reduce voice level (Sapienza, Crandell, \& Curtis, 1999) and the amount of managerial time in physical education settings, at least in the short term (Ryan, 2009). However, such results are obtained only in classrooms with short reverberation times (Shield \& Carey, 2007), indicating that establishing classroom parameters for acoustic measurements is necessary in any classroom prior to installing sound-field systems.

Sound-field systems are often regarded positively by students and teachers, and changes in teachers' subjective ratings of student listening behavior have been noted. Rosenberg et al. (1999) carried out two extensive studies in Florida examining the impact of sound-field systems installation. In Study 1, the impact of amplification was investigated with 1,139 kindergarten, Grade 1, and Grade 2 school students in comparison and amplified classrooms over a period of 12 weeks. Students in amplified classrooms demonstrated significantly greater improvement in listening and learning behaviors, as rated by their teachers, than students in unamplified classrooms. Study 2, which included pre- and posttest assessments, involved 431 students studied over a 4-week period and again indicated that there were significant improvements for the students, as rated by the teachers, after amplification.

Massie and Dillon (2006a, 2006b) reported the results of an Australian study that compared the views of students 
and teachers from 12 primary classrooms when amplification was on and when it was off. In addition to academic gains, which are reported later in this article, teachers completed a rating scale of the students' attention, communication, and classroom behavior following use of the sound-field systems. Teachers reported significant improvements in student behavior with the use of soundfield systems. Similar improvements in behavior have been reported in other studies (e.g., Mulder, 2011), but often there were no comparison or control classrooms so it is not possible to distinguish the impact of the amplification system from other factors such as the passage of time, familiarity with the classroom, or students' development.

Students' ratings of sound-field systems are also positive. Students in the Massie and Dillon (2006b) study reported that they were "happier" when the microphone was used with many students, identifying that they could hear better when the systems were in use. Similarly, Rosenberg et al. (1999) reported that students' ratings to five statements identifying the positive effects of the systems were uniformly high, with $95 \%$ or more affirmative responses about the value of the systems. These data indicate generally positive views about the use of sound-field systems; however, it is not possible to establish whether there are specific tasks such as spoken language or particular listening situations where amplification may be differentially beneficial (Shield \& Dockrell, 2004).

Purdy and colleagues examined the impact of a personal FM system in a sample of 23 students between the ages of 7 and 11 years who were experiencing reading difficulties (Purdy, Smart, Baily, \& Sharma, 2009). Personal FM systems provide each child with an individual amplification system and may, therefore, be more effective than classroom systems. Ratings of ability to hear in difficult classroom situations-for example, hearing a teacher when another teacher was talking-improved with the use of personal amplification and decreased when the amplification systems were removed. Ratings of the students' ability to hear did not differ in other classroom situations. These data point to the potential effectiveness of amplification in specific classroom listening conditions and, by implication, the need for studies to examine ratings over different classroom listening conditions that may be more likely to be improved by the use of sound-field systems.

Fewer studies have reported objective gains in achievement for academic subjects or for specific skills related to academic achievements following the extended use of sound-field systems. Some of the reported work comes from unpublished studies, studies without detailed methodologies, or outputs that are not subject to peer review. For example, a frequently cited study is the "Trost study" (see Millet, 2008, 2009), in which the authors describe reports on a range of literacy measures for students in the amplified classrooms and a group in a nonamplified classroom. However, the lack of data prior to the installation of the amplification systems in the study means that these results may reflect differences in the populations studied rather than the effect of the sound-field systems per se. The majority of systematic experimental work has been with children in the initial stages of formal education (Flexer et al., 2002; Palmer, 1997). In this section, we focus on four experimental studies in which the authors investigated impacts on academic achievement and reported detailed outcome data.

Darai (2000) reported greater literacy gains for first grade children in four classes with amplification as compared with controls over a 5-month period; increases were reported to be greatest for bilingual children and children with additional learning needs, who may be more adversely affected by noise and poor classroom acoustics (Dockrell \& Shield, 2006). Darai (2000) noted that teachers suggested that the students were more attentive to the teacher's voice. However, no data were presented about either the numbers of participants with additional learning needs nor the students' actual baseline performance and follow-up performance. The failure to present baseline performance for the evaluation means that the results must be regarded cautiously, but suggest that sound-field systems may improve reading performance in children at the initial stages of learning to read.

Objective achievement data to support this conclusion have been collected by Massie and Dillon (2006a). They used a crossover design with a sample of 242 Grade 2 students, a large proportion of whom were English-language learners. Acoustic measurements were available for all classrooms. Staff members were trained, and the benefits of the system were explained. During the first semester, half the classes had the soundfield systems on, and the other half had the sound-field systems off. This was reversed in the second semester. By using a crossover design, this study had the benefit of controlling for the effect of passage of time on students' performance. Teachers rated the students' skills using the Queensland education monitoring system (see www. qsa.qld.edu.au/downloads/approach/school-based_ assess_qld_sys.pdf), which examined reading, writing, and numeracy. The sound-field systems provided positive effects in each semester, as rated by the teachers on the outcome measure, and the effect was strongest when averaged across the three skill areas tests. Flexer et al. (2002) focused on the potential added benefit of soundfield systems to a preschool phonological training program. A strength of this pilot study was the focus on the development of a specific skill, phonology, which underpins single-word decoding. Research has consistently shown the benefits of phonological training in relation to reading, and this study compared typical classroom teaching, a phonological intervention, and a phonological 
intervention supported by the use of a sound field system. Although there were indicators that the sound-field systems provided added benefit, there were no statistically significant differences relative to the phonological training program alone. Sample sizes were small, making significance difficult to detect. However, given the reported significant changes in the teacher's voice noted above, this is one skill that ought to benefit from amplification, and, as the authors suggest, further studies of this kind would be beneficial. This is important, as not all studies have found beneficial effects for the systems. Purdy et al. (2009) measured improvement in reading for students who had use of a personal FM in comparison to controls but found no differential benefit of amplification. All students improved over time, with greater improvement when English was spoken at home.

In many cases, the acoustic conditions of rooms in which sound-field systems are to be installed have not been considered. The intelligibility of speech in an enclosed space is related to both the speech-to-noise ratio, which is the difference in decibels between the levels of the received speech signal and the background noise, and the acoustic characteristics of the space. If a room is too reverberant and/or the background noise levels are too high, then the ability of students to hear and understand the teacher will be compromised, whether the speech is natural or amplified. Early reflections of the speech from nearby room surfaces that arrive at the listener's ear within $50 \mathrm{~ms}$ of the direct speech reinforce the speech signal, thereby enhancing speech intelligibility (Department for Education and Skills, 2003). However, if the room is too reverberant, the speech may be masked by later-arriving reflections and speech intelligibility reduced; in addition, the background noise level will increase. It is therefore important that sound-field systems are installed in rooms where the acoustic conditions are suitable for both natural and amplified speech.

The amount of reverberation in a room can be described by the reverberation time ( $R T)$ - that is, the length of time it takes for the sound level to drop by $60 \mathrm{~dB}$ once the source of the sound has ceased. Current regulations regarding the acoustic design of new schools in England and Wales (Department for Education and Skills, 2003) specify that for unoccupied primary school classrooms, the mid-frequency RT (average of RTs at $500 \mathrm{~Hz}, 1000 \mathrm{~Hz}$, and $2000 \mathrm{~Hz}$ ) should not exceed $0.6 \mathrm{~s}$. This is the value also specified in the current U.S. guidelines (ANSI/ASA, 2010) for unoccupied classrooms not exceeding $283 \mathrm{~m}^{3}$ in volume. (All classrooms used in this study had volumes less than this limit.)

\section{Rationale for the Current Study}

Sound-field systems have the potential to mitigate the effects of poor classroom acoustics. In the current review, we have demonstrated that there is a small number of rigorous studies that provide empirical evidence to support the use of sound-field systems, and these studies are beginning to capture the potential loci of the effects of sound-field systems. These studies generally report positive results for behavior, achievement, and views of usage, but data have typically been collected from children in the early stages of elementary school. This study aims to extend previous work by (a) focusing on an older elementary school group; (b) sampling performance on academic and nonacademic tasks that were administered and coded by researchers, not teachers; and (c) attempting to differentiate classroom conditions where amplification may be particularly valuable. In addition, the study collects teachers' views of the impact of amplification and acoustic data of the classrooms.

Use of sound-field systems might enhance learning in a number of ways. Listening in classrooms could be improved, and, as such, it would be predicted that classes using amplification would see gains across academic subjects reflecting enhanced access to classroom teaching. Alternatively, improved SNR could enhance auditory processing, and improved achievements would be expected on verbal but not nonverbal tasks. Finally, amplification may serve to support classroom management and, as a result, affect behavior and attention, resulting in general improvements across classroom performance.

The achievements of elementary school students in amplified and unamplified classrooms over a 6-month period were examined. Acoustic surveys of a sample of classrooms were also conducted. Matched comparison classes with and without installed sound-field systems were identified. Students' perceptions of amplification and their performance on academic tests (reading, spelling, and numeracy), nonverbal tasks (speed of information processing), and listening comprehension (spoken language processing) were assessed prior to the installation of the sound-field systems and after 6 months of use in the target and comparison classrooms. Testing occurred with sound-field systems off to evaluate differential improvement in learning and attention over time.

\section{$\overline{\text { Method }}$}

The study involved questionnaire surveys and experimental testing of students in classrooms with and without sound-field systems, and questionnaires completed by teachers. The sample of students who participated in the study was taken from one county in southeast England that had 458 elementary schools. The local authority had decided to install sound-field systems in every elementary school classroom (for children ages 5-11 years) which, at that point, included or was expected to include a child with a hearing problem. The 
questionnaire surveys and experimental testing of students were carried out before installation of the soundfield systems in target and comparison classrooms (baseline) and 6 months later (posttesting). The project met the ethical guidelines set by the British Psychological Society, and ethical approval was sanctioned by the Institute of Education, London.

\section{School Selection}

We invited the head teachers in all schools in which systems were to be installed in classrooms of children ages 8 years or older to participate in the study. To participate, schools needed to agree to baseline and follow-up measures 6 months later in amplified and comparison classrooms, and acoustic surveys of the classrooms. Originally, 10 schools agreed to participate in the completion of the questionnaires, and six schools agreed to participate in the experimental phase of the study, although valid data from all schools were not available for final analysis. Participating schools were within the average range for national school statistics, including achievement, numbers of students with additional learning needs, and students receiving free school meals. They were in the bottom decile for students learning English as an additional language, as is typical for schools outside major cities in England. Participating classrooms reflected the local authority statistics for both numbers of students learning English as an additional language and students with additional learning needs.

Table 1 shows the eight schools that took part in the study and provided valid questionnaire and experimental data (identified with numbers 1-8) and the classes in each school (identified with letters A-D). The average ages and types of class (i.e., with sound-field systems or comparison classes) are also indicated. The table also shows the measured and estimated RTs, where available, as discussed below.

\section{Participants}

Questionnaire study participants. Students completed a questionnaire before and 6 months after installation of

Table 1. Classrooms included in the different phases of the study and classroom reverberation time (RT) measurements.

\begin{tabular}{|c|c|c|c|c|c|c|}
\hline School & Classroom & Mean age $^{a}$ & Condition & $\begin{array}{c}\text { Student } \\
\text { questionnaire }^{b}\end{array}$ & $\begin{array}{l}\text { Experimental } \\
\text { testing }\end{array}$ & $\begin{array}{l}\text { Mid-frequency } \\
\qquad \mathrm{RT}^{\mathrm{c}, \mathrm{d}}\end{array}$ \\
\hline \multirow[t]{4}{*}{1} & A & $8 ; 0$ & SFS & $*$ & & 0.52 \\
\hline & B & $9 ; 0$ & Comparison & $*$ & & $0.55 \mathrm{E}$ \\
\hline & C & $9 ; 5$ & SFS & $*$ & $*$ & $0.52 \mathrm{E}$ \\
\hline & $D$ & $9 ; 8$ & Comparison & & $*$ & \\
\hline \multirow[t]{3}{*}{2} & A & $8 ; 0$ & SFS & ${ }^{*}$ & & \\
\hline & B & $9 ; 9$ & Comparison & & ${ }^{*}$ & \\
\hline & C & $10 ; 5$ & SFS & $*$ & ${ }^{*}$ & 0.48 \\
\hline \multirow[t]{2}{*}{3} & $A$ & $9 ; 0$ & SFS & $*$ & & \\
\hline & B & $9 ; 6$ & SFS & $*$ & $*$ & $0.41 \mathrm{E}$ \\
\hline 4 & $A$ & $8 ; 9$ & Comparison & & $*$ & \\
\hline \multirow[t]{6}{*}{5} & $A$ & $8 ; 0$ & Comparison & $*$ & & \\
\hline & B & $8 ; 3$ & SFS & $*$ & $*$ & 0.90 \\
\hline & C & $9 ; 0$ & SFS & $*$ & & 0.83 \\
\hline & $D$ & $10 ; 0$ & SFS & $*$ & & 0.55 \\
\hline & $E$ & $10 ; 0$ & Comparison & & & \\
\hline & $\mathrm{F}$ & $10 ; 6$ & SFS & ${ }^{*}$ & $*$ & $0.83 \mathrm{E}$ \\
\hline \multirow[t]{2}{*}{6} & A & $9 ; 0$ & Comparison & ${ }^{*}$ & & \\
\hline & B & $10 ; 0$ & SFS & ${ }^{*}$ & & \\
\hline 7 & $A$ & $10 ; 0$ & Comparison & $*$ & & $0.38 \mathrm{E}$ \\
\hline \multirow[t]{3}{*}{8} & A & $8 ; 0$ & SFS & ${ }^{*}$ & & 0.55 \\
\hline & $B$ & $9 ; 0$ & SFS & $*$ & & $0.55 \mathrm{E}$ \\
\hline & C & $10 ; 0$ & SFS & $*$ & & 0.55 \\
\hline
\end{tabular}

Note. SFS $=$ sound-field systems.

'Students' recorded age in years on the questionnaire. Date of birth at time of testing was collected for the experimental tasks, and age in years and months were calculated. ${ }^{b}$ Asterisks indicate that data were collected in these classrooms. "Mid-frequency RT is the average of RTs at $500 \mathrm{~Hz}, 1000 \mathrm{~Hz}$, and $2000 \mathrm{~Hz}$. " "E" indicates that RT has been estimated from measurements made in similar rooms. 
sound-field systems in their home classrooms. Other students in classrooms without sound-field systems also completed questionnaires at the same time to provide comparison data. In total, 740 students completed baseline questionnaires, and 478 completed questionnaires at follow-up. Data from classes in which soundfield systems had been installed but did not work or were not used were excluded from the analyses. Pupil data available for analysis were from 19 classrooms in seven schools; as shown in Table 1, 14 were rooms that had sound-field systems installed, and five were comparison classrooms. The total number of students for whom baseline and follow-up installation questionnaires were available was 393 . These participants were included in the analyses examining the impact of classroom amplification. Teachers in classrooms with sound-field systems were also asked to complete a questionnaire about the systems when students were completing the follow-up questionnaires.

Experimental study participants. For the experimental study, 186 students ages 8-11 years participated; of these, $15 \%(n=28)$ had special educational needs that had been identified and documented by professionals, and 13\% $(n=25)$ had English as an additional language. Four students were identified with both special educational needs and English as an additional language. The students were from eight classrooms in five schools, five classrooms with amplification $(n=114)$ and three comparison classrooms ( $n=72$ ), as shown in Table 1 . Comparison and sound-field system classrooms did not differ in numbers of students with special educational needs, $\chi^{2}(1, N=186)=0.13, p=.72$, or numbers of students learning English as an additional language, $\chi^{2}(1, N=186)=$ $1.74, p=.42$. Of the five classes in which systems were installed, three classes included students with a hearing problem. In contrast, none of the three comparison classrooms included a child with a hearing problem. Data from students with hearing impairments are not included in the sample and were not analyzed due to the small number $(n=4)$. Students were assessed in their classrooms by a qualified psychologist. Order of presentation of the assessments was randomized. Participants were free to opt out of assessments if they wished.

\section{Assessments \\ Questionnaires}

Students' awareness of 11 environmental noises typically heard in classrooms (see Table 2) and their perceptions of teacher and peer audibility in eight different classroom contexts (see Table 3 ) were examined using a revised version of a previously used classroom listening questionnaire (Dockrell \& Shield, 2004). A smiley face Likert scale was used in which a rating of 1 indicated that the child could hear very well in the condition,
Table 2. Percentage of students reporting environmental sounds in amplified classrooms prior to installation of amplification and 6 months later.

\begin{tabular}{lccc}
\hline $\begin{array}{l}\text { Environmental } \\
\text { sound }\end{array}$ & Baseline & Follow-up & $\chi^{2}$ values $^{\mathbf{a}}$ \\
\hline Cars & 34 & 37 & $(1, N=858)=0.41$ \\
Planes & 53 & 58 & $(1, N=854)=1.63$ \\
Trains & 10 & 8 & $(1, N=854)=0.86$ \\
Phones & 38 & 42 & $(1, N=856)=1.56$ \\
Motorbikes & 33 & 37 & $(1, N=852)=1.69$ \\
Buses & 17 & 15 & $(1, N=854)=0.49$ \\
TV & 24 & 28 & $(1, N=852)=1.87$ \\
Helicopters & 51 & 57 & $(1, N=854)=3.21$ \\
Trucks & 34 & 31 & $(1, N=854)=0.92$ \\
Stereos & 31 & 37 & $(1, N=851)=3.27$ \\
Sirens & 56 & 57 & $(1, N=856)=0.94$ \\
\hline
\end{tabular}

${ }^{\mathrm{a}} \mathrm{All}$ chi-squares were nonsignificant.

and a rating of 5 indicated that it was very difficult to hear.

Teachers in classrooms in which sound-field systems had been installed were asked to complete a questionnaire examining their use of the systems; the classroom activities in which amplification was used; and their rating of the impact of the system on the students' understanding of spoken language, attentiveness in the classroom, and changes in behavior and rate of learning. For the impact items, a Likert scale was used in which a rating of 1 indicated that the teacher strongly disagreed that there was a change and a rating of 5 indicated that the teacher strongly agreed that there was a positive change.

\section{Academic and Cognitive Skills Measures}

We identified measures that have been standardized on U.K. population samples, report reliability, and validity measures in their respective manuals and are used within the U.K. to assess the relevant academic and cognitive domains. Tests were scored by a trained psychologist who did not know whether students were in amplified or comparison classrooms.

Modified versions of standardized tests (British Ability Scales II; Elliott, Smith, \& McCulloch, 1997) for spelling, numeracy, and speed and accuracy of nonverbal processing (Dockrell \& Shield, 2006) and the Suffolk Reading Scale (Hagley, 2002) and listening comprehension test (Hagues, Sissiqui, \& Merwood, 1999) were used. A and B versions were available for each measure, and use of the versions was balanced across classrooms and time of testing.

Reading. The Suffolk Reading Scale (Hagley, 2002) is a standardized reading assessment. Participants are presented with paper booklet comprising 86 items. Each 
Table 3. Mean ratings (and SDs) for the listening environment at baseline and follow-up for students.

\begin{tabular}{|c|c|c|c|c|}
\hline Listening environment & $\begin{array}{c}\text { Baseline } \\
M(S D)\end{array}$ & $\begin{array}{c}\text { Follow-up } \\
M(S D)\end{array}$ & $\begin{array}{c}\text { Baseline } \\
M(S D)\end{array}$ & $\begin{array}{l}\text { Follow-up } \\
M(S D)\end{array}$ \\
\hline 1. Teacher is talking, but you cannot see the teacher's face. & $2.21(0.95)$ & $2.00(0.94)$ & $2.36(1.09)$ & $2.13(0.95)$ \\
\hline 2. Teacher is writing on the board and talking to the class. & $1.91(0.92)$ & $1.69(0.83)$ & $1.97(1.04)$ & $1.91(0.99)$ \\
\hline 3. Teacher is talking and walking around the classroom. & $1.80(0.93)$ & $1.69(0.89)$ & $1.91(0.98)$ & $1.84(0.96)$ \\
\hline 5. Children are making noise outside the classroom. & $2.87(1.08)$ & $2.51(1.08)$ & $2.97(1.08)$ & $2.87(1.02)$ \\
\hline 6. You are doing a test. & $1.52(0.88)$ & $1.33(0.80)$ & $1.54(0.98)$ & $1.24(0.62)$ \\
\hline 7. There is no noise outside the classroom, but there is some noise in the classroom. & $2.56(1.06)$ & $2.45(1.03)$ & $2.54(1.10)$ & $2.49(0.99)$ \\
\hline 8. It is very quiet inside and outside the classroom. & $1.24(0.65)$ & $1.30(0.82)$ & $1.32(0.88)$ & $1.23(0.64)$ \\
\hline
\end{tabular}

Note. Rating scale from 1 (hear very well) to 5 (very difficult to hear).

item is a sentence containing a missing word. Children identify a word to complete the sentence in a semantically correct form from a choice of five. For example: "In hockey we have two types of players, ___ and defenders." The options for this question include attackers, attenders, antagonists, assassins, and assessors. The child silently reads each incomplete sentence and identifies which word out of five should be inserted in the sentence.

Spelling. The British Ability Scales II: Spelling scale (Elliott et al., 1997) provides a number of phonetically regular and irregular words to assess the child's ability to produce correct spellings. There are 25 items in the scale, and each item is presented first in isolation, then within the context of a sentence, and, again, in isolation. The child has to respond by writing the word.

Numeracy. The British Ability Scales II: Numeracy scale (Elliott et al., 1997) is a test of basic computation. Students are presented with a sheet of 25 computations starting with single-digit addition and subtraction and increasing to multiplication, division, and fractions.

Nonverbal processing. The Speed-of-InformationProcessing Test was developed from the British Ability Scales II (Elliott et al., 1997). The scale assesses how quickly the student can perform simple mental operations. Students must process a sequence of circles containing small squares and then decide which circle has the most squares. Each item in the scale consists of a row of circles (three, four, or five), each of which contains a number of small squares (one to four). In our study, there were two versions-each one containing 15 pages, with five items per page - for a total of 75 items. The test was time limited to $2 \mathrm{~min}$. Students recorded their responses by ticking the circle with the most squares in it. Scores were computed for both the number of correct responses and the number of pages completed. We derived an error analysis to examine missed items and incorrect items.
Listening comprehension. The Listening Comprehension Test Series (Hagues et al., 1999) is a standardized test that assesses the communication skills that enable a child to listen, understand, and respond appropriately to information. It includes a section of true/false statements to assess comprehension of passages read orally to the students. It is standardized for students 6 years of age and older. Participants completed two scales comprising 20 items.

\section{Acoustics Survey}

The acoustics survey consisted of two parts. First, we made measurements of room acoustics parameters in 20 typical classrooms in which sound-field systems were to be installed in 10 schools across the county. These measurements indicated the variation in acoustic conditions in rooms in which sound-field systems were to be fitted. Second, where possible, we conducted acoustic surveys of the classrooms included in the questionnaire survey and performed experimental testing.

Each room was unoccupied at the time of the survey. Measurements were carried out in accordance with BS EN ISO 3382:2000 (British Standards Institution, 2000 ), using an omnidirectional source and maximum length sequence procedures to excite the room. In each room, measurements were made at six receiver positions using two source positions, chosen, where possible, to reflect the typical use of the classroom by the teacher. $\mathrm{RT}$ was measured across the octave bands. The values for $500 \mathrm{~Hz}, 1000 \mathrm{~Hz}$, and $2000 \mathrm{~Hz}$ were averaged to give the mid-frequency $\mathrm{RT}, \mathrm{T}_{\mathrm{mf}}$, in accordance with the current acoustic design standards for schools in England and Wales (Department for Education and Skills, 2003). The measurements at each receiver position were spatially averaged to give a single figure for $\mathrm{T}_{\mathrm{mf}}$ for each room. 


\section{Classrooms}

A histogram showing the distribution of midfrequency RTs, $\mathrm{T}_{\mathrm{mf}}$, in the 20 typical classrooms is shown in Figure 1. It can be seen that the sound-field systems were installed in rooms with a wide range of acoustic conditions, including some with a long RT (over $1 \mathrm{~s}$ in one case). Other rooms had very short RTs of less than $0.4 \mathrm{~s}$, where it could be argued that soundfield systems were not necessary as the listening conditions were already very good in those spaces.

The RTs of the study classrooms are shown in Table 1. For various practical reasons (e.g., not being able to gain access to certain classrooms, or noise from construction work taking place in the school out of school hours), acoustic data were measured in only seven of the study classrooms. However, some of the classrooms used were of similar dimensions, volume, construction, design, layout, and surface finishes (e.g., plaster, wood, or glass) to ones that were measured in both parts of the acoustic survey. Where a room was identical or near identical to a measured classroom in terms of size, design, and finishes, it was assumed that the RT would be approximately the same as that of the measured room. In this way, it was possible to estimate the RTs of six additional classrooms, as indicated in Table 1. It can be seen that the RTs of the 13 rooms for which data were available varied from $0.38 \mathrm{~s}$ to $0.9 \mathrm{~s}$.

\section{Results \\ Teacher Questionnaire Following Sound-Field System Installation}

Sixteen teachers from classrooms in which soundfield systems had been installed 6 months previously

Figure 1. Distribution of mid-frequency (average of $500 \mathrm{~Hz}, 1000 \mathrm{~Hz}$, and $2000 \mathrm{~Hz}$ ) reverberation times (RTs) in 20 classrooms with amplification. $\mathrm{T}_{\mathrm{mf}}=$ mid-frequency reverberation time.

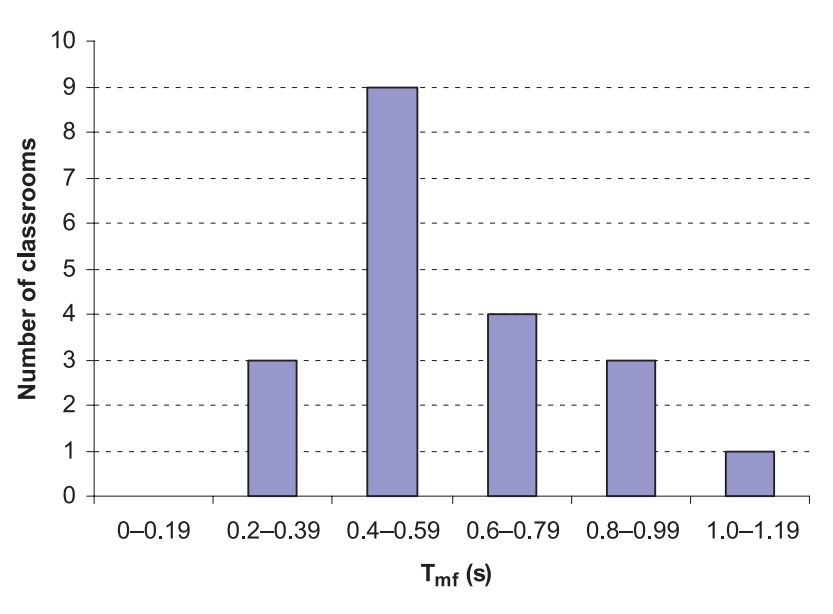

completed the questionnaire. The majority $(n=15)$ had never used sound-field systems previously, and fewer than half $(n=7)$ received training in their use. Only two had been consulted prior to installation about the position of the system. At the time of questionnaire completion, 11 were still using the system, and we report descriptive data from these respondents in terms of their use, benefits of the system, and the changes they noted in their students over the 6 -month period. Of the five who stopped using sound-field systems, three reported that it was uncomfortable to use, and the remaining two reported technical problems.

Of the 11 teachers still using sound-field system, all reported using it daily for at least $40 \%$ of the day. Wholeclass teaching was a primary determinant of use $(n=6)$. Seven teachers used the sound-field systems for all academic lessons, with the remaining four teachers noting that they used it for literacy lessons. Teachers were positive about the effect of sound-field system in supporting students' ability to understand spoken instructions $(n=9)$, their ability to produce more appropriate answers to questions ( $n=8$ ), and the reduced need for the teacher to raise his or her voice $(n=6)$. Improved levels of attention were also noted, with nine teachers noting improved attention spans. In addition, nine teachers noted better attention when there were increased levels of noise. In contrast, there was much more variability in teachers' reports of the impact of the system on the students' academic attainments, with eight teachers noting no changes in the students' rate of learning and nine teachers noting no differences in on-task behavior.

\section{Student Questionnaire Survey}

Overall, the classrooms were rated positively for listening conditions at baseline (mean rating ranges from 1.3 for no noise outside or inside the classroom to 2.9 for students making noise outside the classroom). As predicted and shown in Table 2, the installation of soundfield systems had no significant impact on the students' reported awareness of external sound sources, reinforcing the view that the presence of the sound-field systems did not lead to more positive responding across all questions relating to noise in the classroom environment.

Means and $S D$ s across conditions and time for students' ratings of the classroom listening conditions are presented in Table 3. Independent-samples $t$ tests indicated that the students in the amplified and comparison classrooms did not differ statistically significantly at baseline in their ratings of classroom listening conditions $(t<1.40, n s)$. However, there were significant differences in ratings across listening conditions, $F(7$, $2519)=159.95, p<.001, \eta_{\mathrm{p}}{ }^{2}=.29$, corrected for sphericity with Greenhouse-Geisser. For students in both amplified 
and comparison classrooms, ratings for the quiet classroom (Item 8) were significantly better than for all the other conditions (Bonferonni post hoc $p \mathrm{~s}<.001$ ), whereas ratings for students making noise outside (Item 5) were significantly worse than for all other conditions (Bonferonni post hoc $p \mathrm{~s}<.001$ ).

We expected that the sound-field systems would be of benefit in hearing the teacher in poorer listening conditions (Items 1, 2, 3, 5, and 7) but that effects would be less likely with other situations (Items 4, 6, and 8). We computed two new variables from the mean scores for items on the questionnaire data presented in Table 3: a change-predicted variable (Items $1,2,3,5$, and 7) and a no-change-predicted variable (Items 4, 6, and 8).

A repeated-measures analysis of variance (ANOVA) for the new ratings (change predicted, no change predicted) examined effects of time (baseline and follow-up) and interactions by condition (sound-field systems and comparison). There were significant improvements in ratings of classroom listening for both the changepredicted (baseline, $M=2.29, S D=.69$; follow-up, $M=$ $2.11, S D=.72), F(1,389)=435.90, p<.001, \eta p^{2}=.53$, and no-change-predicted (baseline, $M=1.73, S D=.60$; follow-up, $M=1.63, S D=.58), F(1,389)=4.42, p<.001$, $\eta \mathrm{p}^{2}=.04$, variables. There were no significant two-way interactions by condition, indicating that ratings of classroom listening conditions over time did not differ between students in amplified classrooms and those in comparison classrooms. In sum, students' ratings of their classroom listening environments improved over time, but this was not differentially affected by the use of sound-field systems.

\section{Experimental Tasks}

Students' scores on the experimental tasks at baseline and follow-up are presented in Table 4. Students in the comparison classrooms were significantly younger than the students in the classrooms with sound-field systems (comparison classrooms, $M=9 ; 5$ [years;months], $S D=0 ; 8$; classrooms with sound-field systems, $M=9 ; 8$,
$S D=0 ; 13, t=2.04, d f=131.04, p=.04$, Cohen's $d=$ 0.28 . Therefore, the subsequent analyses control for the age difference between the comparison and amplified classes. A series of ANOVAs controlling for age showed that there were no significant differences for any measures (spelling, numeracy, speed of information processing, accuracy of information processing, reading accuracy, and listening comprehension) between students in the comparison and amplified classrooms at baseline (all $F$ values $<2.00, n s)$.

We first considered the impact of sound-field systems on the accuracy of students' performance on the nonverbal processing test and the verbal listening comprehension measure. Two mixed-design ANOVAs were conducted with time (baseline and follow-up) as the within-subjects factor and amplification (sound-field systems or control) and special educational needs (present or absent) as between-subject factors, with age as a covariate. Where interactions with classroom soundfield systems are nonsignificant, we present $p$ levels for a guide in interpreting the effect and the likelihood of significant results if the sample size were larger. For the nonverbal processing task, there was a significant main effect of time, $F(1,112)=4.82, p=.03, \eta_{\mathrm{p}}^{2}=.04$; a significant interaction with age, $F(1,112)=8.34, p=.005$, $\eta_{\mathrm{p}}{ }^{2}=.07$; and a significant Time $\times$ Condition interaction, $F(1,112)=9.48, p=.003, \eta_{\mathrm{p}}{ }^{2}=.08$, but there was no threeway Special Educational Needs $\times$ Time $\times$ Condition interaction, $F(1,112)=3.00, p=.86$. All other effects were not statistically significant. Figure 2 shows the average number of items correct in the speed-of-processing task before and after installation of sound-field systems for students in the sound-field systems classrooms and the comparison classrooms. As Figure 2 shows, students in classes in which sound-field systems were installed showed a greater improvement in performance on the nonverbal processing task than students in the comparison classes.

In contrast, the ANOVA for listening comprehension revealed no significant main effect of time, $F(1,139)=0.01$, $n s$, and no interaction with age, $F(1,139)=0.04, n s$, but a

Table 4. Mean scores (and SDs) for the academic and cognitive assessments at baseline and follow-up for students.

\begin{tabular}{|c|c|c|c|c|}
\hline \multirow[b]{2}{*}{ Assessment } & \multicolumn{2}{|c|}{ SFS classrooms } & \multicolumn{2}{|c|}{ Comparison classrooms } \\
\hline & $\begin{array}{c}\text { Baseline } \\
M(S D)\end{array}$ & $\begin{array}{c}\text { Follow-up } \\
M(S D)\end{array}$ & $\begin{array}{c}\text { Baseline } \\
M(S D)\end{array}$ & $\begin{array}{c}\text { Follow-up } \\
M(S D)\end{array}$ \\
\hline \multicolumn{5}{|l|}{ Cognitive skills } \\
\hline Listening comprehension & 14.01 (3.49) & $15.50(3.21)$ & $14.81(3.62)$ & $15.00(3.55)$ \\
\hline Nonverbal processing & $48.42(12.95)$ & $61.42(16.90)$ & $48.24(18.74)$ & $51.88(16.81)$ \\
\hline \multicolumn{5}{|l|}{ Academic attainment } \\
\hline Reading & $55.73(10.94)$ & $59.06(11.15)$ & $49.16(15.84)$ & $54.53(13.30)$ \\
\hline Spelling & $21.77(4.08)$ & $22.46(3.66)$ & $18.33(6.83)$ & $19.77(6.70)$ \\
\hline Numeracy & 18.07 (6.09) & $19.36(5.84)$ & $14.67(7.05)$ & $17.14(6.64)$ \\
\hline
\end{tabular}


Figure 2. Mean (and standard error of) numbers of items correct in the speed-of-processing task over 6 months for classrooms with sound-field systems (SFS) and comparison classrooms.

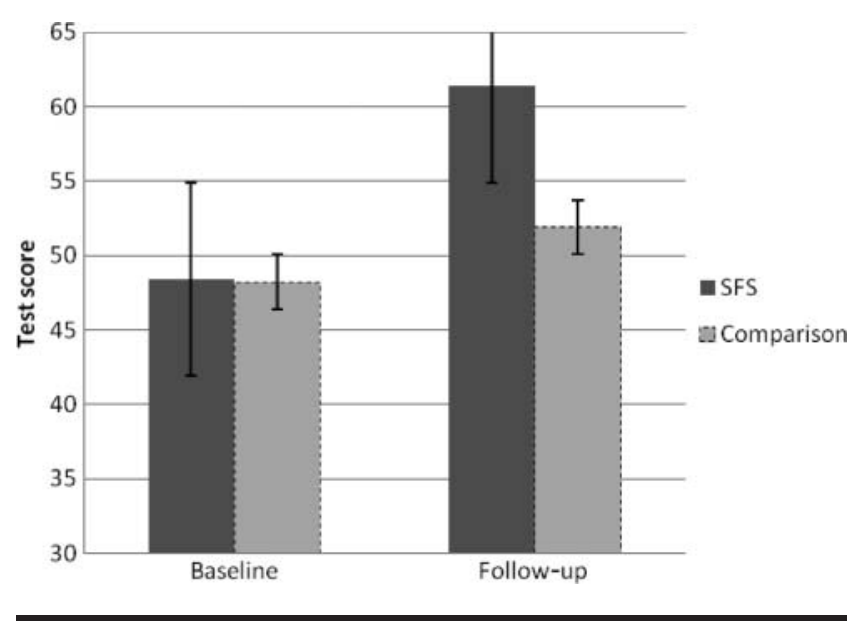

statistically significant Time $\times$ Condition interaction, $F(1,139)=6.51, p=.012, \eta_{p}{ }^{2}=.05$, with no three-way Special Educational Needs $\times$ Time $\times$ Condition interaction, $F(1,139)=0.44, p=.51$. All other effects were not statistically significant. Figure 3 shows the mean scores for the two groups of students before and after installation of the sound-field systems. It can be seen that students in the classrooms with sound-field systems demonstrated an improvement in their listening comprehension score, whereas those in the nonamplified classrooms did not.

Finally, we considered the impact of amplification on students' academic performance. A mixed-design ANOVA was conducted with time (baseline and follow-up)

Figure 3. Mean (and standard error of) listening comprehension scores over 6 months for classrooms with SFS and comparison classrooms.

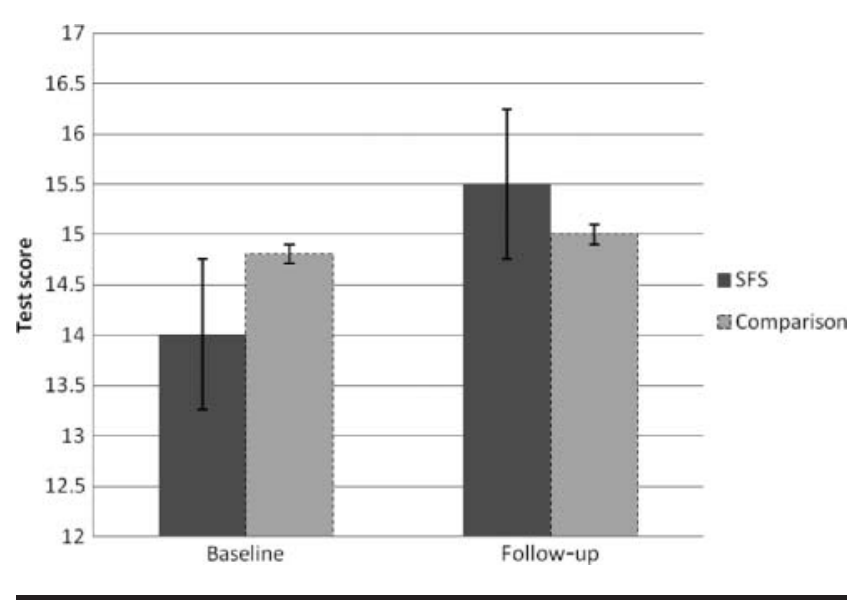

and academic test (reading, spelling, and numeracy) as the within-subjects factors, amplification (soundfield systems or control) and special educational needs (present or absent) as between-subject factors, and age as a covariate. As before, where interactions with classroom sound-field systems are nonsignificant, we present $p$ levels for a guide in interpreting the effect and the likelihood of significant results if the sample size were larger. There was a main effect of time of testing, $F(1,151)=4.80$, $p=.03, \eta_{\mathrm{p}}{ }^{2}=.03$, and a main effect of academic test, $F(2,302)=4.20, p=.02, \eta_{\mathrm{p}}{ }^{2}=.03$. There was also a significant Age $\times$ Test interaction, $F(2,302)=27.52, p<.001$, $\eta_{\mathrm{p}}{ }^{2}=.15$, but not a significant Time of Testing $\times$ Age interaction, $F(1,151)=0.23$, ns. In relation to our predictions, there was no Time of Testing $\times$ Condition interaction, $F(1,151)=0.12, p=.77$, or Test $\times$ Condition interaction, $F(2,302)=0.17, p=.17$. However, there was a trend indicating a three-way Time $\times$ Condition $\times$ Special Educational Needs interaction, $F(1,153)=3.18, p=.07$, $\eta_{\mathrm{p}}{ }^{2}=.02$. Students with special educational needs in the sound-field systems classes made an average gain of 4.1 points $(S E=1.79)$ on academic tests across the 6 months, whereas those in the comparison classrooms made an average gain of 0.02 points $(S E=2.41)$. All other effects were statistically nonsignificant. In summary, as expected, performance on the achievement measures improved over time, but, contrary to our predictions, this improvement was not affected by the use of sound-field systems; however, there was a trend for those students with special educational needs to benefit differentially from the use of sound-field systems.

We had established that three of the five classrooms in which sound-field systems were installed had good acoustics for speech $(\mathrm{RT} \leq 0.52)$. Therefore, we repeated the ANOVAs comparing the gains made in the amplified classrooms between students across time in classrooms with good acoustics and those in classrooms with poorer acoustics ( $\mathrm{RT} \geq 0.83$ ), controlling for age. Three mixeddesign ANOVAs were conducted with time (baseline and follow-up) and speed of processing as the within-subjects factor for the first ANOVA, listening comprehension as the within-subjects factor for the second ANOVA, and academic test (reading, spelling, and numeracy) as the within-subjects factor for the third ANOVA. As the focus of interest is the differential effect of classroom acoustics, we report results only for the interaction between good and poor acoustics. There was no Classroom Acoustics $\times$ Speed-of-Processing Measure interaction, $F(1,75)=2.77, p=.10$. In contrast, for listening comprehension, there was a significant effect of classroom acoustics, $F(1,107)=7.73, p=.006, \eta_{\mathrm{p}}{ }^{2}=.07$. Students in the classrooms with poorer acoustics made an average gain of $2.44(S E=0.47)$ correct answers, whereas those in the classrooms with good acoustics made an average gain of $0.86(S E=0.40)$ correct answers. There was 
no Academic Test Scores $\times$ Classroom Acoustics interaction, $F(2,230)=0.04, p=.33$.

\section{$\overline{\text { Discussion }}$}

The current study aimed to evaluate the use of sound-field systems in elementary schools in one English local authority. Data were available to examine teachers' views of the systems, compare students' evaluation of classroom listening conditions over time in classes with and without sound-field systems installed, and evaluate changes in cognitive skills and academic performance over time. Together, these measures tap the range of factors reported to be improved when classroom amplification is used.

The listening conditions questionnaire used in this study is a subjective measure that is sensitive to different acoustic conditions (Dockrell \& Shield, 2004). Overall, students had rated their classrooms as good listening environments, and these ratings improved over time. We had predicted no differences between the amplified and comparison classrooms in the environmental noises students reported hearing, as amplification does not affect external noise. There were no significant differences between students in amplified classrooms and those without sound-field systems, so this prediction was upheld. In contrast, we had predicted that students in amplified classrooms would produce better ratings for teacher audibility, but this prediction was not upheld. There was no evidence to support improved ratings of teacher audibility; that is, there were no differential effects over time for those in amplified and nonamplified classrooms, although there were increases in students' perceptions of audibility over time. The inclusion of appropriate comparison groups is crucial to understanding these patterns of responses. If we had omitted the comparison group, increased ratings of classroom listening over time would have erroneously been attributed to a specific effect of sound-field systems. Students' improved ratings of the listening features of their classrooms over time may reflect increased familiarity with the classrooms and their teachers' voices. In addition, students may have developed strategies to minimize difficulties they had in listening in their classrooms (Dockrell \& Shield, 2004).

We had predicted that if sound-field systems improved the academic achievement of students in the classrooms, we would expect greater improvement across all academic subjects - that is, reading, spelling, and numeracy -in classes with sound-field systems compared with comparison classrooms. Students' performance did improve over time, indicating that they had been learning during the interim 6 months, but there was no evidence to support a differential effect for students in amplified classrooms. Neither was there evidence to support the view that all tasks that are verbally mediated (listening comprehension, spelling, and reading) were improved in comparison to nonverbal tasks (numeracy and speed of processing). Finally, we had predicted that, if the use of these systems improved the learning environment, attention and the processing of spoken language would show differential improvements along with the academic tasks. This did not occur. Thus, overall, there was no evidence to support the specific hypotheses that were made about the ways in which amplification could improve the learning environments in these classrooms.

We did find significant benefits in the amplified classrooms for the listening comprehension task and the nonverbal speed-of-information-processing task, accounting for $5 \%$ and $7 \%$ of the variance, respectively. Overall, performance on the listening comprehension measure did not improve significantly over the 6-month period. There was, however, a differential effect in which improvement was evident only for students in the amplified classrooms. Therefore, the listening comprehension differential gain may reflect either improved listening in difficult situations or the strategies implemented by the teacher. The fact that this improvement was specific to classrooms with poorer acoustics suggests that the impact of sound-field systems was moderated by the specific classrooms; for students in classrooms with excellent speech intelligibility, there was little to gain. This effect was not expected (see Shield \& Carey, 2007). It is possible that improving aspects of speech intelligibility (possibly improved SNR) in the classrooms with poorer acoustics led to relative improved performance on this spoken task. Alternatively, as suggested by Darai (2000) and reported by the teachers in this study, students may be more attentive to the teacher's voice, and this strategy may be particularily beneficial in classrooms with poorer acoustics.

This does not explain the differential improvement in speed of information processing between amplified and comparison classrooms. It is possible that soundfield systems helped the teacher maintain the students' attention and that, over time, their approach to work had improved, and this was evident on a task that required speed and attention to detail. These are performance factors reported to be specifically vulnerable to exposure to noise (Evans \& Lepore, 1993; Shield \& Dockrell, 2008). However, performance on this speeded task did not differ between amplified classrooms with good and poorer acoustics, supporting the view that changes in teacher (or student) behavior are a more likely explanation. Teachers who chose to use sound-field systems may have been more aware of the need to monitor the attention and listening of their students. It is also possible that schools with sound-field systems were less exposed 
to the types of noises that interfere with speeded nonverbal tasks (Dockrell \& Shield, 2006), although this was not evident in the students' ratings.

Our sample included students with certified special educational needs in experimental and comparison classrooms. We examined the extent to which their performance differed from mainstream peers without documented learning difficulties. It is known that students with special educational needs are often vulnerable in the area of processing verbal material, and this is frequently evidenced in terms of poor phonological skills (Bradlow, Krauss, \& Hayes, 2003; Dellatolas, Kremin, De Agostini, Martin, \& Dupuis, 2002). Previous work has shown that this vulnerability is exacerbated in acoustically marginal classrooms. As expected, we found no differential performance for students with special educational needs on the nonverbal processing measure. Contrary to predictions, we also found no differential effect for listening comprehension; however, our sample of students with special educational needs was small. Despite the small sample size differential, performance in academic attainments was evident. The current results indicate that the use of sound-field systems may serve to minimize the impact of poorer acoustics on the academic attainments of vulnerable learners. The students with special educational needs in the current study made virtually no progress on our academic measures over the 6 -month period when sound-field systems were not in use. In contrast, gains were noted when sound-field systems were used. This trend in differential improvement for students with special educational needs warrants further systematic research and points to the ways in which modifications of the acoustic environment might support learning and attainments.

\section{Study Limitations}

Examining students' performance in classroom settings over time raises a number of methodological challenges, including assumptions about causal mechanisms of change, ensuring a sufficiently large sample is recruited, and problems with implementation. The use of sound-field systems was not continued in some of the experimental classrooms in this study, and teachers of some comparison classrooms were not willing to be involved in the repeat assessments 6 months later. Thus, class and subject attrition reduces the power of the samples and is a potential bias in the results. Moreover, despite that the local authority provided training, some teachers reported not being sufficiently trained in the use of the systems, thereby reducing the potential efficacy of sound-field systems. In further larger studies, researchers will need to consider these factors in the design. Practical limitations in the school environment also meant that it was not possible to obtain all the acoustic measurements that we would have wished from target classrooms. It is possible that improvements to the acoustic conditions of classrooms with poor acoustics-for example, by the installation of acoustically absorbent materials to reduce $\mathrm{RT}$ rather than the use of soundfield systems - would have a similar beneficial effect by improving speech intelligibility. A further study is required in which the two approaches to mitigating the effects of poor classroom acoustics are compared. Finally, in studying the impact of sound-field systems, researchers need to systematically address students with special educational needs with a larger sample size and a more detailed profile of the difficulties that the students experience to confirm the benefits that we have identified for this group of students.

\section{$\overline{\text { Conclusions }}$}

In the current study, we found specific effects in classrooms in which sound-field systems were used, but these effects were small and subtle. The gain in the spoken comprehension measure suggests that improved speech-to-noise ratio in classrooms with poorer acoustics may be responsible for these results, but further studies are required to substantiate this effect. Of paramount importance is the need to consider the acoustics of the classrooms. Students in this study rated their classroom acoustic environments positively, which is consistent with the relatively low values of $\mathrm{RT}$ that were measured. Further work needs to consider the specific acoustic parameters of the classroom as an additional variable in the measurement of the benefits of sound-field systems and link predicted changes in behavior to theoretical models of language processing and learning in classrooms.

\section{Acknowledgments}

This research was funded by the Engineering and Physical Sciences Research Council, United Kingdom. We gratefully acknowledge the assistance of Kate Rigby and Ann Carey. We thank all the children and teachers for their time and effort.

\section{References}

American National Standards Institute/Acoustical Society of America. (2010). Acoustical performance criteria, design requirements, and guidelines for schools: Part 1. Permanent schools (ANSI/ASA 12.60-2010/Part 1). New York, NY: Author.

Bradley, J. S., \& Sato, H. (2008). The intelligibility of speech in elementary school classrooms. The Journal of the Acoustical Society of America, 123, 2078-2086.

Bradlow, A. R., Krauss, N., \& Hayes, E. (2003). Speaking clearly for children with learning disabilities: Sentence 
perception in noise. Journal of Speech, Language, and Hearing Research, 46, 80-97.

British Standards Institution. (2000). Acoustics: Measurement of the reverberation time of rooms with reference to other acoustical parameters (BS EN ISO 3382:2000). London, England: Author.

Cohen, S. (1980). After effects of stress on human performance and social behavior: A review of research and theory. Psychological Bulletin, 88, 82-108.

Cohen, S., Evans, G. W., Krantz, D. S., \& Stokols, D. (1980). Physiological, motivational, and cognitive effects of aircraft noise on children: Moving from the laboratory to the field. American Psychologist, 35, 231-243.

Cohen, S., Krantz, D. S., Evans, G. W., Stokols, D., \& Kelly, S. (1981). Aircraft noise and children: A longitudinal and cross-sectional evidence on adaption to noise and the effectiveness of noise abatement. Journal of Personality and Social Psychology, 40, 331-345.

Cohen, S., \& Weinstein, N. (1981). Non-auditory effects of noise on behavior and health. Journal of Social Issues, 37, 36-70.

Darai, B. (2000, July 10). Using sound field FM systems to improve literacy scores. Advances for Speech-Language Pathologists and Audiologists: ALD Applications, 10 (27), $5,13$.

Dellatolas, G., Kremin, H., De Agostini, M., Martin, S., \& Dupuis, C. (2002). Learning to read in children: Two exploratory studies. Revue de Neuropsychologie, 12, 457-485.

Department for Education and Skills. (2003). Acoustic design of schools (Building Bulletin 93). London, England: TSO. Retrieved from www.teachernet.gov.uk/acoustics.

Dockrell, J. E., \& Shield, B. (2004). Children's perceptions of their acoustic environment at school and at home. The Journal of the Acoustical Society of America, 115, 2964-2973. doi:10.1121/1.1652610 | issn 0001-4966

Dockrell, J. E., \& Shield, B. M. (2006). Acoustical barriers in classrooms: The impact of noise on performance in the classroom. British Educational Research Journal, 32, $509-525$.

Elliott, C. D., Smith, P., \& McCulloch, K. (1997). The British Ability Scales II. Windsor, United Kingdom: NferNelson.

Evans, G. W., \& Lepore, S. J. (1993). Nonauditory effects of noise on children: A critical review. Children's Environments, 10, 31-51.

Flexer, C., Biley, K., Hinckley, A., Harkema, C., \& Holcomb, J. (2002). Using sound-field systems to teach phonemic awareness to pre-schoolers. The Hearing Journal, $55(3), 38-44$.

Hagley, J. F. (2002). The Suffolk Reading Scale. Windsor, United Kingdom: GL-Assesment.

Hagues, N., Sissiqui, R., \& Merwood, P. (1999). Listening Comprehension Test Series. Windsor, United Kingdom: NferNelson.

Jónsdottir, V. (2010, June). Is amplification necessary in a classroom? Paper presented at Inter-Noise 2010: 39th International Congress on Noise Control Engineering, Lisbon, Portugal.

Jónsdottir, V., Laukkanen, A., \& Siikki, I. (2003). Changes in teachers' voice quality during a working day with and without electric sound amplification. Folia Phoniatrica et Logopaedica, 55, 267-280.

Larsen, J. B., \& Blair, J. C. (2008). The effect of classroom amplification on the signal-to-noise ratio in classrooms while class is in session. Language, Speech, and Hearing Services in Schools, 39, 451-460. doi:10.1044/0161-1461 (2008/07-0032)

Massie, R., \& Dillon, H. (2006a). The impact of sound-field amplification in mainstream cross-cultural classrooms: Part 1. Educational outcomes. Australian Journal of Education, 50, 62-77.

Massie, R., \& Dillon, H. (2006b). The impact of sound-field amplification in mainstream cross-cultural classrooms: Part 2. Teacher and child opinions. Australian Journal of Education, 50, 78-94.

McSporran, E. (1997). Towards better listening and learning in the classroom. Educational Review, 49, 13-20.

Millett, P. (2008). Sound field amplification research summary. Retrieved from http://research.epicoustics.com/ sound_field_amplification_research_summary.pdf.

Millett, P. (2009). Using classroom amplification in a universal design model to enhance hearing and listening (Research Monograph 23). Retrieved from www.edu.gov.on.ca/eng/ literacynumeracy/inspire/research/WW_Classroom_ Amplification.pdf.

Mulder, H. (2011). Dynamic soundfield: Teachers' ratings. Retrieved from http://www.phonakpro.com/content/dam/ phonak/b2b/C_M_tools/Library/Field_Study_News/en/ FSN_DynamicSoundField-Teacher_Ratings-2011_04.pdf.

Palmer, C. V. (1997). Hearing and listening in a typical classroom. Language, Speech, and Hearing Services in Schools, $28,213-218$.

Picard, M., \& Bradley, J. S. (2001). Revisiting speech interference in classrooms. Audiology, 40, 221-244.

Purdy, S. C., Smart, J. L., Baily, M., \& Sharma, M. (2009). Do children with reading delay benefit from the use of personal FM systems in the classroom? International Journal of Audiology, 48, 843-852. doi:10.3109/14992020903140910

Rosenberg, G., Blake-Rahter, P., Heavner, J., Allen, L., Redmond, B., Philips, J., \& Stigers, K. (1999). Improving classroom acoustics (ICA): A three-year FM sound field classroom amplification study. Journal of Educational Audiology, 7, 8-28.

Ryan, S. (2009). The effects of a sound-field amplification system on managerial time in middle school physical education settings. Language, Speech, and Hearing Services in Schools, 40, 131-137. doi:10.1044/0161-1461(2008/08-0038)

Sapienza, C. M., Crandell, C. C., \& Curtis, B. (1999). Effects of sound-field frequency modulation amplification on reducing teachers' sound pressure level in the classroom. Journal of Voice, 13, 375-381.

Shield, B., \& Carey, A. (2007, September). Measurement of teachers' voice levels in primary school classrooms. Paper presented at the 19th International Congress on Acoustics, Madrid, Spain.

Shield, B., \& Dockrell, J. E. (2004). External and internal noise surveys of London primary schools. The Journal of the Acoustical Society of America, 115, 730-738. doi:10.1121/ 1.1635837 | issn 0001-4966 
Shield, B. M., \& Dockrell, J. E. (2008). The effects of environmental and classroom noise on the academic attainments of primary school children. The Journal of the Acoustical Society of America, 123, 133-144. doi:10.1121/1.2812596 | issn 0001-4966
Stansfeld, S. A., Berglund, B., Clark, C., Lopez-Barrio, I., Fischer, P., Ohrstrom, E., ... Team, R. S. (2005). Aircraft and road traffic noise and children's cognition and health: A cross-national study. The Lancet, 365, 1942-1949. 
The Impact of Sound-Field Systems on Learning and Attention in Elementary School Classrooms

Julie E. Dockrell, and Bridget Shield

J Speech Lang Hear Res 2012;55;1163-1176; originally published online Jan 9, 2012;

DOI: $10.1044 / 1092-4388(2011 / 11-0026)$

This information is current as of September 2, 2012

This article, along with updated information and services, is located on the World Wide Web at:

http://jslhr.asha.org/cgi/content/full/55/4/1163 